\title{
Using Binary Logistic Regression to Predict Long-term Effects of Early-Age Home Literacy Environment on Reading Motivation
}

\author{
Taoufik Boulhrir* \\ Department of English Studies, Discourse, Creativity, and Society, USMBA, Saiss-Fes, Morocco \\ *Corresponding author: Taoufik.boulhrir@usmba.ac.ma
}

\begin{abstract}
Home literacy environment has ubiquitously been investigated against its impact on academic achievement and reading motivation. This study is an investigation of the long-lasting effects of home literacy environment on Moroccan students' reading motivation. 178 students aged 14-24 were surveyed online to elicit their early-age home literacy experiences and to test them against the odds of their reading motivation. Using data gathered on such environments and experiences, a binary logistic regression inferential test was conducted to test if students who grow up in literacy-rich home environments are more likely to be motivated readers, and vice versa. The purpose of using this test in particular is to find out whether reading motivation can be predicted based on home literacy environment data. The accuracy of prediction of this test can be indicative of its potential to detect and diagnose reading motivation at various academic levels. As far as findings of this study are concerned the BLR test affirms that the odds of reading motivation being tied to HLE factors are significantly high. Using BLR to predict, diagnose, and intervene may help educators, parents, and curricula developers in considering HLE and early-age literacy experiences in policy making and curricula designs.
\end{abstract}

Keywords: reading motivation, home literacy environment, binary logistic regression

Cite This Article: Taoufik Boulhrir, "Using Binary Logistic Regression to Predict Long-term Effects of Early-Age Home Literacy Environment on Reading Motivation.” American Journal of Educational Research, vol. 5, no. 8 (2017): 858-862. doi: 10.12691/education-5-8-4.

\section{Introduction}

Home literacy environment, counter to common belief, may play a pivotal role in promoting literacy and reading skills in children during their early years of schooling through adolescence to adulthood. Home literacy environment which research has proven to have a significant impact on literacy learning and academic achievement may also have a pivotal role in developing and fostering reading motivation [1]. There are numerous ways in which home literacy environment can affect emergent literacy in children upon their enrolling in school, as well as afterwards as they grow as learners in general, and as readers in particular. One way to do so is to investigate students' early-age home literacy experiences against their self-reported reading motivation. This study uses Binary Logistic Regression to determine the odds of participants' reading motivation in connection to their HLE and whether they are motivated readers, or not. Hence, the focal question of this investigation is: how does early-age home literacy environment affect the odds of students (not) being motivated readers?

\section{Literature Review}

Numerous researchers give much credence to the effects of home literacy environment on reading skills and motivation. There is a well-grounded argument that avid young readers tend to come from homes where reading and literacy is not only part of their daily lives, but a lifestyle. They are "good" homes where "story time" is a routine that provides parents and their children opportunities to engage in conversations and meaningful reading that enriches imagination and creativity [2]. Homes where "their parents must have instilled in them the love of reading long before they learned to read independently and at their leisure" [2]. The argument is that children who grow up in a literacy rich environment acquire a number of skills that are directly related to reading independently as well as reading motivation. Yet, the question may still remain: how can parents provide such an environment that provides practices and opportunities for children to develop such skills? Reading to children as a routine implies that the practice could be more of a cultural behavior that is inherited generation after generation. It reflects a social perspective that grants reading a high status of importance.

Environmental reading literacy practices include a myriad of visually rich, cognitively stimulant, and relevantly available connections to meaningful print. For example, families may enrich their homes with reading habits, coloring tools, books, magazines, and posters, to name a few. Provision of such items familiarizes young children with the world of literacy and prepares them for 
reading. Rich environments incite children's curiosity and engage them in exploring the world of print which, in turn, instills the motivation and the skills they will need in their school [3]. In addition, parents need to bear in mind that their own practices go definitely along with their provision of literacy opportunities; that is, their children cannot longitudinally acquire the habit of reading without the parents demonstrating those habits at home.

Work that dates back to the early 80s, instigated interest in "family literacy" as a major drive towards the success rates of children in school. A study of six American families and their "continuously diffuse use of written language in the ongoing life of the family" [4] revealed that their early year literacy practices had a vivid influence of their children's success in school. A similar finding was reported for further support of the correlation between the occurrence of literacy knowledge and skills gained in the home and literacy expectations, hence achievement occurrence in school [5].

Therefore, it is important to bear in mind that parents need to work towards providing the appropriate environment for their children's literacy to prosper, especially if parents' expectations of school performance is high [6]. The relationship between parents' expectations, attitudes, and academic achievement is argued to be evident in the correlation between "children's reading performance [in school and] the amount of reading done by their parents" [1]. This correlation can further be explained by the fact that the quality and the accessibility of print and other literacy tools, in addition to parents' consistent reading habits constitute an ideal environment for children to follow and engage in similar activities. Once this engagement is encouraged and supported by the parents, it creates an intrinsic motivation in reading which, in turn, leads to acquisition of reading and other cognitive skills that are necessary for academic achievement [7] [8].

A qualitative study investigated the effects of Home literacy and parental expectations in five 3-6 years old Chinese-American children and revealed that parents had a strong impact on their children's emergent literacy skills and their motivation to learn [9]. This study analyzed data that consisted of written products, observations, and interviews with parents and their children. It concluded that Chinese parents instill the love of reading in English and Chinese by means of modeling and exposing them to a variety of literacy experiences at a very early age. Such early age experiences pave the way for children to excel in school. This feature in Chinese homes is reported to have a tremendous effect on children's "school language" acquisition and bilingual learning of reading on the long run [9].

Undoubtedly, recent and earlier literacy studies have repeatedly found that home literacy environments have a tremendous impact on academic achievement in early schooling life of children, chiefly reading. Many Scholars and researchers agree that high rates of children's academic achievement correlate with the quality and the richness of literacy in their homes $[10,11]$. Parents who play an amalgam of roles at home - being role models, teachers, or literacy opportunities providers - manage to help their children achieve literacy and academic skills before and/or during their school years. In a recent quantitative study, a synthesis of analyses of the Progress in International Reading Literacy Study (PIRLS) test reveals striking correlations between early literacy experiences and developing later literacy [12]. The study concludes that, "children who enter school having been read to at home scored, on average, 35 points higher than children whose parents did not read to them [13].

If the results and PIRLS conclusions about the correlation between home literacy environment (mainly reading to children at home) and PIRLS scores are valid, then it can be predicted that this could be applicable to Morocco. Because Morocco is one of the participating countries the scores of which were among the lowest, then it can be predicted that this may be linked to a low literacy environment, or simply put, Moroccan parents generally do not tend to provide a literacy rich environment for their children.

Research suggests that reading literacy begins in a home environment where literacy is promoted in various ways. A rich literacy environment does not only foster children's literacy skills and motivation, but it also prepares them for school. By the time they reach schooling time, children who are nurtured in a literacyrich environment seem to be readier than those who come from literacy-deprived environments. The relationship between the quality of the home literacy environment and the school/academic achievement is evident. Children who grow in a family where reading literacy is promoted, encouraged, and nurtured tend to do well in school in the sense that they carry out a learning process they have already started in the home.

Nevertheless, it is worth noting that not all families have the educational means to create the aforementioned literacy environments and tools to facilitate the development of reading skills in their children. Some parents do not even have the required education level that permits them to transfer reading skills to their children. Early studies in the sixties and early seventies found that the level of parents' education attainment is directly or indirectly related to the extent to which children are exposed to literacy in their homes, and therefore, related to their (the children's) literacy development before and during schooling years $[14,16]$. Likewise, recent research on parenting has also shown that there is a direct correlation between educational levels in parents and their students' literacy levels and academic achievement [16]. Hence, this present investigation seeks to find out if parents' educational levels have an impact on the quality of home literacy environment which will be examined against the odds of reading motivation. This will also be elicited as a home environment variable from students to see if it correlates with their motivation to read in their respective classrooms.

\section{Method}

Data for this investigation was gathered using an online quantitative survey launched over three months targeting students aged 14-24 in Morocco. The questionnaire elicited information from about home literacy environment that included: 1) parents' educational attainment, 2) parents' reading habits, 3) using a home library, and 4) pre-school reading experiences. Home literacy environment 
was measured using Likert scales to produce an accumulative score that ranged between 0-16.

The survey also contained a binary question about whether participants were motivated readers or not. The dichotomous outcome of this question was tested in terms of the probability of its occurrence being tied to the HLE variables. For this purpose, a Binary Logistic Regression inferential test was conducted to measure the odds of being motivated is an outcome of a rich home literacy environment, and vice versa.

\section{Data Analysis}

Survey results on whether reading was one of the participants' favorite activities indicate that $34.27 \%$ identified themselves as motivated, whereas the majority (65.73\%) categorized themselves as unmotivated. Figure 1 depicts the rates of each category. This variable is essential to this study because it is a binary outcome that is to be tested against the levels of home literacy environment variable in the Logistic Regression test.

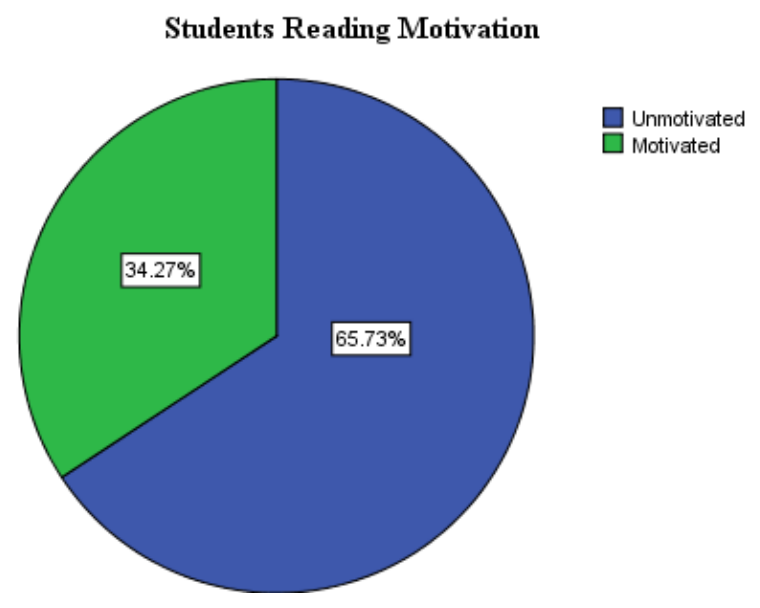

Figure 1. Motivated vs. Unmotivated Readers

To answer this study's question, the inferential statistical test needs to be explained and justified in terms of its basic assumptions and methods of application before interpreting the results. This question deals with a dichotomous dependent variable (Motivated vs. Unmotivated) which is expected to be an outcome of an ordinal independent variables (HLE, 0 - 16) score. In order for this test to accurately predict the odds of an outcome variable to occur based on the explanatory variables (IV), certain assumptions need first to be met. Most researchers stress two main assumptions underlying the use of Binary Logistic Regression: the nature of the dependent binary variable's distribution and the nature of relationship between this variable and the independent variable [13]. "Under the first assumption, it is presumed that each of the potential values of the outcome variable Y ( 0 or 1$)$, has a corresponding expected probability that varies as a function of the values that the independent variable(s) can take for each subject" [13]. These assumptions require that "the same probability is maintained across the range of predictor values” [14].

To assess the soundness of a BLR model, the researcher needs to assess the predicted probabilities in a way that "the resultant predicted probabilities can [...] be validated with the actual outcome to determine if high probabilities are associated with events and low probabilities with nonevents” [14]. Goodness-of-fit test checks the accuracy of the BLR steps in predicting the odds of participants being motivated, or not. Hence, the inferential HosmerLemeshow's "classification table is most appropriate when classification is a stated goal of the analysis; otherwise it should only supplement more rigorous methods of assessment of fit” [15]. Table 1 portrays the degrees of accuracy of prediction by comparing the observed values to the expected values, only to support the soundness of the model being used in this investigation. Results of this test portray a high level of accuracy in predictions; all the observed and expected occurrences for motivated and unmotivated are near in value to one another.

Table 1. Goodness-of-fit Contingency Test

\begin{tabular}{|c|c|c|c|c|c|c|}
\hline \multicolumn{7}{|c|}{ Contingency Table for Hosmer and Lemeshow Test } \\
\hline \multirow{2}{*}{\multicolumn{2}{|c|}{$\begin{array}{l}\text { Reading } \\
\text { Motivation }\end{array}$}} & \multicolumn{2}{|c|}{$=$ Unmotivated } & \multicolumn{2}{|c|}{$=$ Motivated } & \multirow{2}{*}{$\begin{array}{c}\mathrm{N} \\
178\end{array}$} \\
\hline & & Observed & Expected & Observed & Expected & \\
\hline \multirow{8}{*}{ Step 1} & 1 & 2 & 1.991 & 0 & .009 & 2 \\
\hline & 2 & 61 & 60.373 & 0 & .627 & 61 \\
\hline & 3 & 30 & 30.239 & 1 & .761 & 31 \\
\hline & 4 & 16 & 16.515 & 3 & 2.485 & 19 \\
\hline & 5 & 7 & 6.937 & 11 & 11.063 & 18 \\
\hline & 6 & 1 & .786 & 14 & 14.214 & 15 \\
\hline & 7 & 0 & .149 & 21 & 20.851 & 21 \\
\hline & 8 & 0 & .010 & 11 & 10.990 & 11 \\
\hline
\end{tabular}

The last and most important step in the process is the classification plot which visually presents data of the classification table (step 1) with some finer details. This provides visual guidance to how accurate the model is by indicating how accurate the model predicts a 'yes' outcome based on predicted probability calculations when in fact the outcome (motivated vs. unmotivated) was 'no'. When the model is good at predicting the outcome for individual cases, the plot shows a bunching of the occurrences toward the left and right ends of the graph. In fact, Figure 2 illustrates this gathering of observations towards the left and right ( 0 and 1 respectively), which indicates a high level of accuracy in predicting the probabilities of membership of "motivated", and by default "unmotivated".

Step 1 reveals that the Coefficient $(\mathrm{B})$ is $.885(\neq 0)$, $p$-value is $.000(\mathrm{p}<0.05)$, and that $\operatorname{Exp} \mathrm{B}$ is 2.422 (see Table 2). What is most important in this table is $\operatorname{Exp}(\mathrm{B})$, the exponentiation of the $\mathrm{B}$ coefficient, which is also referred to as the odds ratio. It tells the researcher how much the odds increase multiplicatively with change by one-unit in the independent variable. If the $\operatorname{Exp}(\mathrm{B})$ is positive, the relationship is so too. Therefore, addition of 1 point/unit in the independent variable (HLE) score increases the likelihood/odds of a case/student to be motivated by 2.422. Simply put, the odds of a student being motivated are 2.42 times higher with each (1-point) increase in the HLE score. The percentage of increase in this model is $142 \%$ and it is calculated as follows:

$$
100(\text { Exp B }-1) \rightarrow 100(2,42-1)=142 \% \text {. }
$$




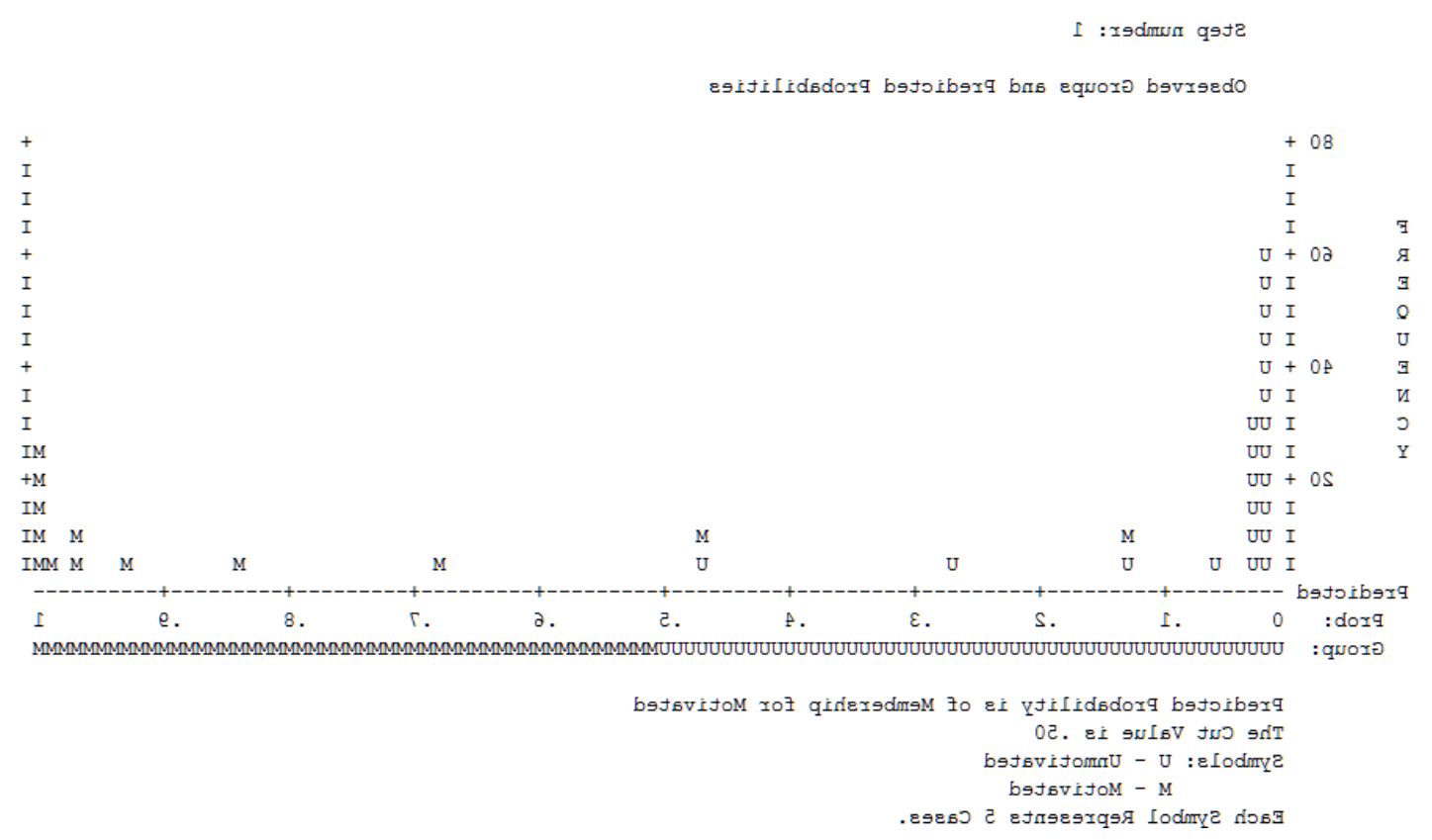

Figure 2. Classification Plot for Observed and Predicted Membership Probability

Table 2. Model of the Equation (predictors entered)

\begin{tabular}{|c|c|c|c|c|c|c|c|c|}
\hline \multicolumn{9}{|c|}{ Variables in the Equation } \\
\hline \multirow{2}{*}{ Step 1} & \multirow{2}{*}{ B } & S.E. & \multirow{2}{*}{ Wald } & $\mathrm{df}$ & \multirow{2}{*}{ Sig. } & \multicolumn{4}{|c|}{$95 \%$ C.I. } \\
\cline { 5 - 10 } & & & & & & Exp(B) & Lower & Upper \\
\hline HLE score & .885 & .141 & 39.483 & 1 & .000 & 2.422 & 1.838 & 3.192 \\
\hline Constant & $-5.451-$ & .847 & 41.382 & 1 & .000 & .004 & & \\
\hline
\end{tabular}

All in all, a binary logistic regression test was performed to predict the odds of 178 students being (un)motivated using HLE score as predictor. The test of a full model against a null (intercept only) model was statistically significant, indicating that the predictors as a set reliably and correctly categorized motivated and unmotivated students $92.7 \%$ of the time. Results of the predictors models $(\operatorname{ExpB}=2.42, \mathrm{p}=.00<.05, \mathrm{df}=1)$ indicate that with each unit increase in the HLE score, the likelihood of a being motivated increases by 2.42 times. Therefore, it can be concluded that home literacy environment affects the likelihood of being (un)motivated.

\section{Discussion}

The accuracy of the prediction process indicated in the results is intriguingly interesting. Although it was predicted in the hypothesis that the odds would be significant, the fact that the prediction of the likelihood of a binary outcome to be predicted at an accuracy rate of $92.7 \%$ is quite significant. This is important to consider not only in future research but also in diagnosis of reading motivation, instructional differentiation and placements of learners upon their entry to school, regardless of their academic levels [17]. Being able to predict the level of motivation in students based on their early-age home literacy environments and experiences data could be a breakthrough in education, if more similar studies find the relationship to be evident in different contexts.

As matter of fact, numerous research studies find a connection between some elements of HLE and reading motivation to be quite significant. For instance, an investigation of the impact of parents' expectation on learning and reading motivation in five 3-6 years old Chinese-American children found the relationship to be strong [9]. These findings are supported by another study that asserts that exposing babies and infants to reading experiences is one of the most effective ways to enhance linguistic and literacy development [16]. Back in 2001, The National Centre for Research in Children Literature (NCRCL) examined data gathered about babies who were read-to at home in the Bookstar program to find that such babies were $600 \%$ more likely to be public library members in the future. The fact that these studies focus their interests on specific aspects of home literacy environments calls for more research to be done for the sake of uncovering more relationships between the variables at hand.

For the sake of discussion, it can be argued that homes with the highest scores in home literacy environment have the tendency to develop and foster reading motivation in children. This effect as shown in this study lasts through adolescence and adulthood which underscores the importance of early-age literacy experiences in developing a bonding relationship with reading. Using a logistic regression test can not only find the relationship between different factors and outcomes, but it can also flag problems of reading at entry levels of any educational setting. Such diagnosis process may help in initiating interventional programs that target struggling/unmotivated readers. In line with this, predicting the level of reading skill and motivation in educational settings seems to be given credence by both teachers and students in the sense 
that the relationship between the two variables (HLE and Reading) has proven to be significant.

\section{Conclusion}

A logistic regression test was set forth to measure the likelihood of students being motivated readers (or not) based on the quality of their home literacy environments and early childhood literacy experiences. The test confirmed the research hypothesis which predicted that students who come from literacy-rich homes and who have had positive preschool experiences were more likely to be motivated readers, and vice versa. This is indicative of the importance of home literacy environment and the roles of parents' attitudes, habits, and practices in developing and fostering reading motivation in the long run. At the age of formal schooling, children are expected to know basics of literacy and teaching practices that aim to nurture these skills by means of teaching practices that enhance intrinsic reading motivation. Using the BLR test to detect reading difficulties, and predict reading motivation in students may be of great value to educational institutions, teachers, and parents, and particularly students. This test, hence, could be useful for research binary data analysis and beneficial in predicting potential literacy and academic hardships at entry levels of educational institutions. As proven in this study, early-age home literacy experiences may have an effect on reading motivation that could last throughout adolescence and adulthood. If literacy issues could proactively be predicted by means of analyzing background home environment data, more and better interventional procedures and strategies could be put in place for the benefit of the learner.

\section{References}

[1] Hess, R. D., Holloway , S., Price, G. G., \& Dickson, P. W. (1980). Family Environments and the Acquisition of Reading Skills. New York: Plenum.
[2] Monroe, B. J. (2004). Crossing the Digital Age: Race, Writing, and Technology in the Classroom. New York: Teachers College Press.

[3] Delgado-Gaitan, C. (1990). Literacy for Empowerment: The Role of Parents in Children's Education. London: Falmer Press.

[4] Taylor, D., \& Dorsey- Gaines, C. (1988). Growing up Literate: Learning from Inner-city Families. Portsmouth, NJ: Heinemann.

[5] Garcia , G. E., \& Pearson, D. P. (1990). Modifying Reading Instructionto Maximize its Effectiveness for all Students. Champaign: Center for the Study of Reading.

[6] Cairney, T. H. (2003, July 30). Literacy within Family Life. Retrieved May 1, 2014, from http://trevorcairney.com/: http://trevorcairney.com/wp-content/uploads/2012/11/Hall-08.pdf.

[7] Wigfield, A., \& Asher , S. A. (1983, Novermber 3). Social and Motivational Influence on Reading . Retrieved May 6, 2014, from www.ideals.illinois.edu.

[8] Teale, W. H., \& Sulzby, E. (1986). Emergent Literacy as a Perspective for Examining How Young Children Become Writers and Readers. Norwood, NJ: Ablex.

[9] Cheng, S.-T. (2003). Home Literacy Practices: The Emergent Literacy Experience of Five Chinese Children in America. Loyola Univeristy Chicago . Chicago, Illinois: UMI.

[10] Britto, P. R. (2001, December). Family Literacy Environments and Young Children's Emerging. Retrieved May 2, 2014, from http://www.proquest.com/.

[11] Burgess, S. R., Hecht, S. A., \& Lonigan, C. J. (2002, October). Relations of the Home Literacy Environment (HLE) to the Development of Reading-Related Abilities: A One-Year Longitudinal Study. Retrieved May 25, 2014, from https://www.jstor.org.

[12] Sege, E. (2013, April 4). Early Experience Shapes Later Literacy. Retrieved May 5, 2014, from https://eyeonearlyeducation.com.

[13] Cabrera, A. F. (1994). Logistic Regression Analysis in Higher Education: An Applied Perspective. In J. C. Smart , Higher Education: Handbook of Theory and Research (pp. 225-256). New York: Agathon Press. Retrieved from http://www.education.umd.edu/.

[14] Durkin, D. (1966). Children who Read Early. New York: Teacher's College Press.

[15] Hosmer, D. W., \& Lemeshow, S. (2000). Applied Logistic Regression . New York : John-Wiley \& Sons, Inc.

[16] Loasa, L. M. (1978, December ). Maternal Teaching Strategies in Chicano Families of Varied Educational and Socioeconomic Levels. Retrieved January 14, 2013, from www.jstor.org.

[17] Boulhrir, T. (2014). Raising Achievement for All Students (RAFA): Differentiation. Presentation, Center for British Teachers: ADEC Tamkeen Program, Abu Dhabi, UAE. 